\title{
Penile Skin Flap Urethroplasty for Urethral Stenosis at Sominé DOLO Hospital of Mopti (MALI)
}

\author{
Dramane Cissé1,2*, Honoré Jean Gabriel Berthé1,3, Abdoulaye Traoré1,2, \\ Mamadou Lamine Diakité1,3, Modibo Coulibaly1,2, Mory Koné1,2, Djibril Traoré1,2, \\ Bréhima Traoré1,2, Diamilatou Thiam 1,4, Mamadou Tidiani Coulibaly1,5, Alkadri Diarra1,6, \\ Amadou Kassogué1,7, Moussa Salifou Diallo1,7, Oumar Guindo1,2 \\ ${ }^{1}$ Université des Sciences des Techniques et des Technologies de Bamako, Bamako, Mali \\ ${ }^{2}$ Hôpital Sominé DOLO de Mopti, Mopti, Mali \\ ${ }^{3} \mathrm{CHU}$ du Point G Bamako, Bamako, Mali \\ ${ }^{4}$ Direction Régionale de la Santé de Mopti, Mopti, Mali \\ ${ }^{5} \mathrm{CHU}$ Gabriel TOURE Bamako, Bamako, Mali \\ ${ }^{6} \mathrm{CHU}$ Luxembourg, Bamako, Mali \\ ${ }^{7} \mathrm{CHU}$ Kati, Kati, Mali \\ Email: ^djennecisse@yahoo.fr, berthonore@hotmail.com, diakite.mlamine@hotmail.fr, modibocoulibaly@yahoo.com, \\ Konemory@gmail.com,ngoaabdoulaye@yahoo.fr, Dtdjibsonl28@gmail.com, Ibt_61@yahoo.fr, diamilath2@yahoo.fr, \\ mamadoutc@yahoo.fr, Bamako.dralkadri@yahoo.fr, amadouenet@yahoo.fr,mousalifon@gmail.com, barugdo@yahoo.fr
}

How to cite this paper: Cissé, D., Berthé, H.J.G., Traoré, A., Diakité, M.L., Coulibaly, M., Koné, M., Traoré, D., Traoré, B., Thiam, D., Coulibaly, M.T., Diarra, A., Kassogué, A., Diallo, M.S. and Guindo, O. (2021) Penile Skin Flap Urethroplasty for Urethral Stenosis at Sominé DOLO Hospital of Mopti (MALI). Open Journal of Urology, 11, 240-250.

https://doi.org/10.4236/oju.2021.117022

Received: May 22, 2021

Accepted: July 6, 2021

Published: July 9,2021

Copyright $\odot 2021$ by author(s) and Scientific Research Publishing Inc. This work is licensed under the Creative Commons Attribution International License (CC BY 4.0).

http://creativecommons.org/licenses/by/4.0/

(c) $\underset{\mathrm{By}}{\text { (i) Open Access }}$

\begin{abstract}
Introduction: Penile skin flap urethroplasty is a technique for replacing or enlarging an obstructed urethra. We aim to report our experience in the practice of this surgical technique. Patients and method: This was a prospective and descriptive study of penile skin flap urethroplasty indicated for urethral stenosis between January 2014 and December 2019. Results: A total of 21 penile skin flap urethroplasties for urethral stenosis were performed. The average age was 38.6 years old. The stenosis was of sclero-inflammatory origin in 15 cases $(71.43 \%)$. It was of bulbo-perineal, penile, and penile-bulbar topography in about a third each. A history of urethral surgery was reported in $80.95 \%$ of the cases. The average length of the stenosis was $6.8 \mathrm{~cm}$. Mundy circular skin flap urethroplasty about 15 cases (71.43\%), and Quartey rectangular skin penile flap urethroplasty about 6 cases (28.57\%) were the surgical techniques performed. The postoperative follow-up was favorable in 19 cases (90.48\%). Two cases of urethral fistula $(9.52 \%)$ underwent the $2^{\text {nd }}$ urethroplasty. Urination at 1 year was satisfactory. No relapse has been reported to date. However, 4 patients (19.04\%) reported asthenic ejaculation, and 1 patient $(4.76 \%)$ a marked decrease in sexual pleasure. Conclusion: This surgical
\end{abstract}


technique is effective in terms of voiding when the surgical indications are well chosen. The sexual aspect must be taken into account and the intervention only offered to those who really need it.

\section{Keywords}

Urethral Stenosis, Urethroplasty, Pedicled Flap

\section{Introduction}

Stenosis of the urethra is a permanent decrease in the size of the urethra, due to non-neoplastic morphological changes in its wall. Its clinical translation is difficult or even an impossibility for the patient to empty his bladder. It is responsible for impaired life quality due to its complications particularly, urinary tract infection, bladder stone, fistulas, sepsis, and kidney failure [1]. A distinction is made between spongy or anterior urethral stenosis and stenosis of the posterior urethra of traumatic origin. Spongy or anterior urethral stenosis is pathology of alteration and scarring of the urethral wall, more or less long, and most often it's of sclero-inflammatory etiology. The incidence of urethral stenosis is estimated at 200 to 1200 cases per 100,000 men [1]. The therapeutic means consist of urethral dilation, urethrotomy, and reconstructive surgery techniques [2]. In the literature, it is accepted that short urethral stenosis of fewer than 2 centimeters $(\mathrm{cm})$ is treated by excision of the stenosis followed by end-to-end anastomosis [3]. Urethral stenosis beyond $2 \mathrm{~cm}$ managed by an anastomotic urethroplasty could lead to the risk of shortening of the penis and especially of curvature of the penis for stenosis of the penile urethra [4]. Complex structures of the anterior urethra should benefit from a urethral reconstruction technique using free or pedicle autograft [5] [6]. At the end of the 1990s, urethroplasty by a buccal mucosal graft had become the reference treatment in reconstructive surgery of the urethra for long urethral stenosis because of its advantageous histological properties and especially because of its results [7]. Nevertheless, it has some drawbacks such as the double site of intervention, the intervention of another specialist for the safe harvesting of the buccal mucosa. Sometimes, complications of the sampling site occurred. Last but not least, general anesthesia is required for buccal graft sampling and urethral surgery. With a similar functional result between urethroplasty by buccal mucosal graft and urethroplasty by penile skin flap [8] [9] [10] [11] and due to the conditions of wider use due to the vascularization of the flap, our team opted for urethroplasty by a penile skin flap in the first intention to treat long and or complex shrinkage of the male anterior urethra. It is a surgical technique to replace or enlarge the urethra by a flap of the skin of the penis or of the pedunculated foreskin on the cellulovascular tissue of the penis. The main objective of this study was to report our experience in the practice of this surgical technique in our hospital. 


\section{Patients and Methods}

This was a prospective and descriptive study of male patients who underwent penile skin flap urethroplasty for urethral stenosis between January $1^{\text {st }}, 2014$, and December 31, 2019, in our hospital. All patients with single or multiple urethral strictures greater than $2 \mathrm{~cm}$ without urethral fistula were included except stenoses due to atrophic lichen sclerosus. All patients underwent retrograde voiding and antegrade urethra-cystography for patients with a cystostomy, to measure the length of the stenosis, and to assess the alteration of the ureteral wall. All patients underwent a cytobacteriological urinalysis with antibiogram and the urine-born infections (UBIs) detected were treated before any surgical planning. All patients received a preoperative assessment and an explanation of the principle and procedure of the intervention as well as any possible complications and side effects after the intervention. Informed consent of all patients was obtained prior to surgery planning. In the operating room, a supine position was used for stenosis of the penile urethra and a waist position for stenosis of the bulbar urethra. Patients were under locoregional or general anesthesia, and antibiotic prophylaxis. All interventions were carried out by a team of 3 urologists including a senior present at all interventions.

We performed flap urethroplasty pedicled penile which breaks down as shown in Figure 1 into:

- Placement of a lubricated probe to locate the narrowed part;

- Incision straddling the narrowed part and dissection of subcutaneous cellular tissue and/or muscle up to the urethra;

- Release of the urethra at the level of the narrowed part all around and opening of the wall at the level of the stenosis to a healthy and flexible area;

- Measurement of the stenosis and excision of the entire pathological urethra and all neighboring pathological tissues;

- Measurement on the skin of the penis at the level of its dorsal part or of the foreskin of the length of the stenosis increased by $20 \%$;

- First distal incision on the penis which crosses all the layers until contact with the albuginea of the cavernous bodies, then dissection continued until the root of the penis;

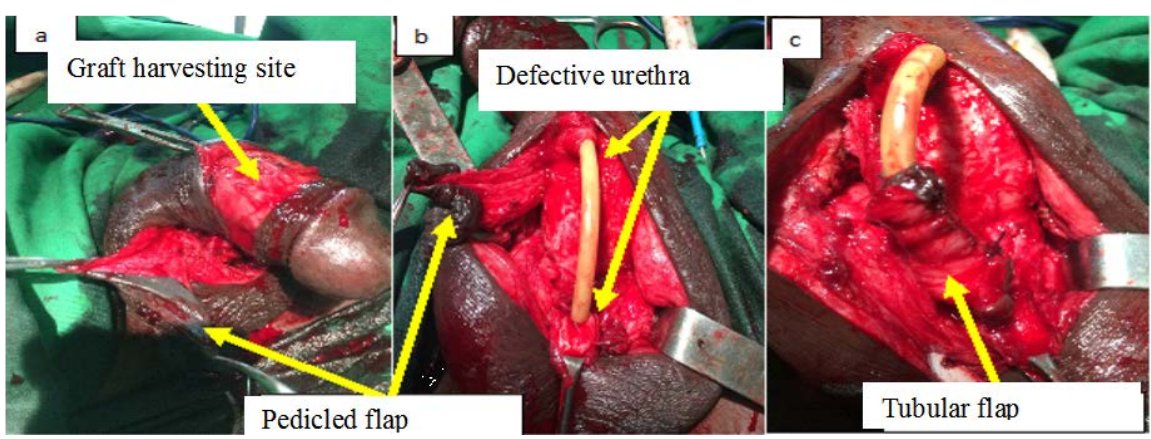

Figure 1. Pedicled penile flap urethroplasty. (a) Taking the flap from the dorsal side of the penis; (b) Flap brought back to the ventral surface of the penis; (c) Tubular flap. 
- Second superficial incision taking only the skin, below the first and delimiting the width of the flap, separating the skin from the vascular subcutaneous tissue. This dissection is also continued down to the root of the penis, thus delimiting the pedicled flap (Figure 1(a));

- Mobilization of the pedicle flap is brought back into contact with the penile urethra or the bulbar urethra through a peno-perineal tunnel (Figure 1(b));

- Tubularization of the cutaneous part of the flap by inverting points on the dartos, around a probe of variable size depending on the size of the healthy urethra (Figure 1(c));

- Spatulation of the proximal and distal part of the healthy urethra to obtain a larger anastomosis zone;

- End-to-end anastomosis of the tubularized flap to the urethra, around a catheter whose balloon is inflated in the bladder, the suture line of the flap tubularization being placed in the dorsal position;

- Layer by layer closure of donor site and the urethral pathway.

All patients received antibiotic therapy with intravenous ceftriaxone 1gramme twice daily for 3 days and oral relay therapy with cefixime $400 \mathrm{mg}$ as a single dose for 10 days. Dressings, good oral hydration, and mobilization from the $3^{\text {rd }}$ postoperative day constituted the bulk of postoperative care. The urethra-vesical catheters were kept for 21 days. Patients were followed every 3 months for one year, and then asked to come for a medical consultation after 1 year whenever they noticed a change in voiding comfort. This follow-up consisted of a history, physical examination, and direct assessment of urination. The intervention was considered successful if the patient had good voiding flow and had not had any other stenosis treatment procedure. Good urination was characterized by an immediate onset, a jet drawing a parabola, a frank ending without late drops and an absence of abdominal thrust.

Data were collected from the patient's medical record, and the operative reports. Epidemiological, diagnostic and therapeutic data were recorded. Data were analyzed by using SPSS software.

\section{Results}

In 6 years, 21 penile skin flap urethroplasties for urethral stenosis were performed. Several urethroplasty techniques have been used depending on the length of the stenosis, the presence of fistula or depending on the existence of suppuration. Among these surgical techniques, penile skin flap urethroplasty accounted for $19.44 \%(21 / 108)$.

Penile skin flap urethroplasty also represented 1.04\% (21/2130) of all urosurgeries. The annual distribution of penile skin flap urethroplasties is shown in Figure 2.

The mean age was $38.6 \pm 12.3$ years with the extremes ranging from 11 to 59 years. The dilation with $33.33 \%$ was the most carried out treatment antecedent. The sclero-inflammatory etiology with $71.43 \%$ was the most common. The mean 
Annual distribution of urethroplasties

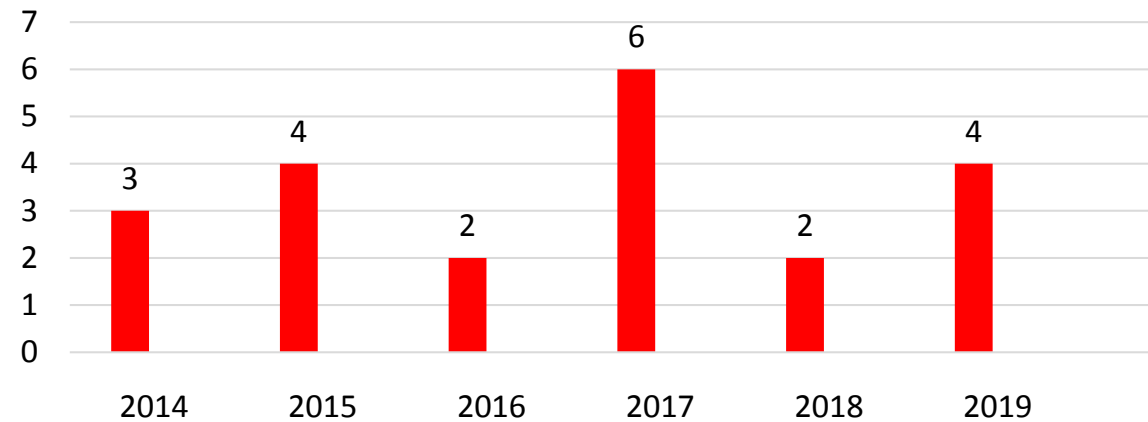

Figure 2. Annual distribution of urethroplasties.

length of the stenosis was $6.8 \pm 2.1 \mathrm{~cm}$ with the extremes ranging from 3 to 12 $\mathrm{cm}$. The topography was bulbo-perineal in $38.1 \%$ of cases. In Table 1, the characteristics of the stenosis before urethroplasty are highlighted.

The anesthetic mode was spinal anesthesia in 20 cases (95.24\%) and general anesthesia in 1 case (4.76\%). Mundy's penile skin flap urethroplasty 15 cases (71.43\%), and Quartey's rectangular penile skin flap urethroplasty 6 cases (28.57\%) were the surgical techniques performed. The postoperative follow-up was favorable in 19 cases (90.48\%), 2 cases of urethral fistula (9.52\%) underwent second urethroplasty. The mean duration of follow-up was 41.21 months. The urination at 1 year of follow-up was satisfactory. No relapse has been reported to date. However, 4 patients (19.04\%) reported asthenic ejaculation and 1 patient $(4.76 \%)$ a marked decrease in sexual pleasure.

\section{Discussion}

The anterior urethra is poor healing tissue due to the presence of spongy tissue. A wound by infectious or traumatic origin weakens the urethral mucosa and causes urine output to the spongy body which gets irritated and inflames on a larger dimension. The healing process results in an exaggeration of the scar tissue whose epicenter represents the stenosis part of the urethra. The extent of the spongy body disease is not always known, and several lesions at different stages of development can cause the stenosis to recur at another site even after proper treatment. Recurrence is also the rule in all treatment methods that leave the pathological urethra in place. Because of all these difficulties, many surgical techniques were developed without having a good efficiency until the advent of tissue transfer techniques initiated by Orandi [12] and especially Quartey for the pedicled graft [13] [14]. Since then, several modified techniques have emerged either by the shape of the graft, circular Mundy flap, or the graft harvesting area, scrotal graft for Gategno, perineal for Blandy, and penis fascia for Mac Aninch [15] [16]. These different techniques have not been able to completely suppress the phenomenon of excessive scarring at the graft-urethra junction. Ten years later, techniques using free grafts of oral mucosa and allowing such an exploit were born [17] [18]. Given that the retrospective studies have shown no significant 
Table 1. Characteristics of stenosis.

\begin{tabular}{|c|c|c|}
\hline Variables & Fequency & $\%$ \\
\hline \multicolumn{3}{|l|}{ Age in years } \\
\hline $10-15$ & 1 & 4.76 \\
\hline $16-30$ & 2 & 9.52 \\
\hline $31-45$ & 11 & 52.38 \\
\hline $46-60$ & 7 & 33.34 \\
\hline Total & 21 & 100 \\
\hline \multicolumn{3}{|l|}{ Etiology } \\
\hline Sclero-inflammatory & 15 & 71.43 \\
\hline Iatrogenic & 3 & 14.28 \\
\hline traumatic & 2 & 9.52 \\
\hline Trophic & 1 & 4.77 \\
\hline \multicolumn{3}{|l|}{ Topography } \\
\hline Bulbar & 8 & 38.01 \\
\hline Penile & 7 & 33.33 \\
\hline Staged (Penile and Bulbar) & 6 & 28.57 \\
\hline Total & 21 & 100 \\
\hline \multicolumn{3}{|l|}{ Stenosis lenght in $\mathrm{cm}$} \\
\hline $3-5$ & 11 & 52.39 \\
\hline $6-8$ & 7 & 33.33 \\
\hline $9-11$ & 2 & 9.52 \\
\hline More than 11 & 1 & 4.76 \\
\hline Total & 21 & 100 \\
\hline \multicolumn{3}{|l|}{ Antecedents } \\
\hline Urethral dilation & 7 & 33.33 \\
\hline Urethroplasty & 6 & 28.57 \\
\hline Endoscopic internal urethrotomy (EIU) & 4 & 19.05 \\
\hline No history & 4 & 19.05 \\
\hline Total & 21 & 100 \\
\hline
\end{tabular}

difference between the two techniques, the choice of teams will be made according to the facilities of each.

The average age of our patients was 38.6 years. Our patients were younger than in most studies. It was 44.4 years in Burkina [19], 45 years in Tunisia [20], 45.2 in Egypt [21]. Stenosis of the urethra is pathology of young adults. Inflammatory etiology is most common in Africa [21]. Infectious urethritis contracted early in the sexual experience is responsible for urethral obstruction 10 to 15 years later. The etiology was infectious in $71.43 \%$ of the cases in our study; it was most frequent with 52\% in Tunisia [20] and 42\% in Egypt [21]. In developed 
countries, the etiology is traumatic and iatrogenic [22] [23]. In our study, a case of trophic stenosis extending from the urethral meatus to the penoscrotal angle was diagnosed in an 11-year-old child. He had a long history of dysuria with the impossibility of probing whatever the caliber of the catheter and a threadlike urine stream. The site of postinfectious urethral stenosis is the anterior urethra. In our study, it was bulbar in about a third of the cases, penile and bulbo-penile in a third each. The site was bulbar in $90 \%$ and $3 \%$ of the penile site in Tunisian series [20] and bulbar-penile in $60.5 \%$ of cases in Egyptian series [21]. The larger bulbar urethra is a storage site for secretions after intercourse and is therefore the preferred site for postinfectious urethral stenosis. One of the particuliarities of post-infectious shrinkage is the length of the stenosis, unlike post-traumatic stenosis, which is shorter and is more treated with endoscopic internal urethrotomy (EIU) or anastomotic urethroplasty [3]. Recurrence of short stenosis after EIU or after dilation usually results in longer shrinkage due to urine entering the spongy body through the intrusion of the urethral membrane caused by the treatment. An anastomotic urethroplasty can also cause a longer recurrence due to the healing process but also insufficient excision of the pathological tissue, apparent or not. About $80 \%$ of our patients had a history of treatment for the stenosis by either anastomotic urethroplasty, urethral dilation, or EIU. This treatment history rate was $89 \%$, including $65 \%$ of EIU for a study carried out in Tunisia [20].

The mean length of the stenosis was $6.8 \mathrm{~cm}$. It was higher than the Tunisian series [20] which was $5 \mathrm{~cm}$ and lower than Egyptian series [21] which was 10.7 $\mathrm{cm}$. Penile skin flap urethroplasty is a suitable technique to replace a pathological urethra from the navicular fossa to the membranous urethra [20]. This technique has long been used to create a missing urethra in often posterior hypospadias before finding its indication in urethral stricture. The virtual absence of hair on the skin of the penis or the foreskin has allowed the technique to supplant other flaps such as the scrotal skin of Gatégno and the perineal skin of Blandy since these flaps can be blocked by the growth of hair which in its turn could promote the lithogenesis.

The flexibility of the skin of the penis and its supporting tissue allows it to be mobilized to the level of the bulbar urethra.

The choice of surgical technique in our study depended on the length of the stenosis. Regarding a penile skin flap in all cases, Mundy's circular flap was chosen whenever the length of the stenosis was greater than $4 \mathrm{~cm}$. This technique generally allows the choice of a longer and wider flap. The rectangular flap of Quartey has been indicated in stenosis less than or equal to $4 \mathrm{~cm}$. These two techniques allowed us to have a success rate of $90.48 \%$ for an average follow-up of 41.21 months. However, we recorded 2 early failures by suppuration and fistulization. In these patients, antibiotic therapy was started according to the antibiogram. Also, early catheter removal and sitz baths were performed, transforming the one-step urethroplasty to a 2-step urethroplasty, the flap having played the role of an open urethra sutured to the skin. 
Our result is similar to those of several studies in the literature where success rates range from $70 \%$ to $90 \%$ [9] [20] [21] [24] [25].

Our follow-up was active for 1 year with an appointment every three months. After one year, the patients were asked to seek a medical consultation when they experience a decrease in the urinary stream or in voiding comfort. Patient agreement on this method of monitoring was obtained and implemented, especially since the majority of them had a history of treatment for the same pathology. For the cured patients, no complaints regarding urination were noted; the complaints mainly concerned the sexual function of the urethra. Four patients reported drooling asthenic ejaculation with no saccade and decreased sexual pleasure, while one patient reported a marked decrease in sexual pleasure. The urethra has a sexual function; its replacement can have repercussions on ejaculation, especially in long stenosis. In urethral replacement, in order to prevent a recurrence, one is tempted to take a longer and wider flap than necessary. Such an attitude can be responsible for urethral diverticulum, urine leakage after the end of urination, and asthenic ejaculation. The size of the flap must be $20 \%$ greater than the length of the stenosis according to the formula: Flap length $=$ (US + $\left(U^{*} 0.2\right)$ ) [26]. Notice that US stands for Urethral Stenosis. In a study conducted in Egypt [21], the pseudo diverticulum neourethra was found in $7.6 \%$ of cases and late post-voiding drops in $23 \%$ of cases.

\section{Conclusion}

We used tubularized penile skin flap successfully in one stage in our patients. Its indication in the treatment of long non-fistulized urethral stenoses gave very good results. Despite its good voiding result, the flap cannot fulfill the sexual function of the original urethra; therefore its indications must be strict and only intended for those who really need it.

\section{Conflicts of Interest}

The authors declare no conflicts of interest regarding the publication of this paper.

\section{References}

[1] Santucci, R., Joyce, G.F. and Wise, M. (2007) Male Urethral Stricture Disease. The Journal of Urology, 177, 1667-1674. https://doi.org/10.1016/j.juro.2007.01.041

[2] Barbagli, G., Sansalone, S., Djinovic, R., Romano, G. and Lazzeri, M. (2012) Current Controversies in Reconstructive Surgery of the Anterior Urethra: A Clinical Overview. International Brazilian Journal of Urology, 38, 307-316. https://doi.org/10.1590/S1677-55382012000300003

[3] Andrich, D.E., Dunglison, N., Greenwell, T.J. and Mundy, A.R. (2003) The LongTerm Results of Urethroplasty. The Journal of Urology, 170, 90-92. https://doi.org/10.1097/01.ju.0000069820.81726.00

[4] Lee, Y.J. and Kim, S.W. (2013) Current Management of Urethral Stricture. Korean Journal of Urology, 54, 561-569. https://doi.org/10.4111/kju.2013.54.9.561 
[5] Abuzeid, A.M. and Abdel Kader, M.S. (2012) Reconstruction of Long Anterior Urethral Strictures by Dorsally Quilted Penile Skin Flap. ISRN Urology, 2012, Article ID: 651513. https://doi.org/10.5402/2012/651513

[6] Levine, L.A., Strom, K.H. and Lux, M.M. (2017) Buccal Mucosa Graft Urethroplasty for Anterior Urethral Stricture Repair: Evaluation of the Impact of Stricture Location and Lichen Sclerosus on Surgical Outcome. The Journal of Urology, 178, 20112015. https://doi.org/10.1016/j.juro.2007.07.034

[7] Lumen, N., Oosterlinck, W. and Hoebeke, P. (2012) Urethral Reconstruction Using Buccal Mucosa or Penile Skin Grafts: Systematic Review and Meta-Analysis. Urologia Internationalis, 89, 387-394. https://doi.org/10.1159/000341138

[8] Soliman, M.G., Abo Farha, M., El Abd, A.S., Abdel Hameed, H. and El Gamal, S. (2014) Dorsal Onlay Urethroplasty Using Buccal Mucosa Graft versus Penile Skin Flap for Management of Long Anterior Urethral Strictures: A Prospective Randomized Study. The Scandinavian Journal of Urology, 48, 466-473. https://doi.org/10.3109/21681805.2014.888474

[9] Dubey, D., Vijjan, V., Kapoor, R., Srivastava, A., Mandhani, A., Kumar, A., et al. (2007) Dorsal Onlay Buccal Mucosa versus Penile Skin Flap Urethroplasty for Anterior Urethral Strictures: Results from a Randomized Prospective Trial. The Journal of Urology, 178, 2466-2469. https://doi.org/10.1016/j.juro.2007.08.010

[10] Fu, Q., Zhang, Y., Zhang, J., Xie, H., Sa, Y.L. and Jin, S. (2017) Substitution Urethroplasty for Anterior Urethral Stricture Repair: Comparison between Lingual $\mathrm{Mu}$ cosa Graft and Pedicled Skin Flap. The Scandinavian Journal of Urology, 51, 479483. https://doi.org/10.1080/21681805.2017.1353541

[11] Hussein, M.M., Almogazy, H., Mamdouh, A., Farag, F., Rashed, E., Gamal, W., et al. (2016) Urethroplasty for Treatment of Long Anterior Urethral Stricture: Buccal Mucosa Graft versus Penile Skin Graft-Does the Stricture Length Matter? International Urology and Nephrology, 48, 1831-1835. https://doi.org/10.1007/s11255-016-1366-0

[12] Orandi, A. (1968) One-Stage Urethroplasty. British Journal of Urology, 40, 717-719. https://doi.org/10.1111/j.1464-410X.1968.tb11872.x

[13] Quartey, J.K. (1983) One-Stage Penile/Preputial Cutaneous Island Flap Urethroplasty for Urethral Stricture: A Preliminary Report. The Journal of Urology, 129, 284-287. https://doi.org/10.1016/S0022-5347(17)52051-0

[14] Quartey, J.K. (1985) One-Stage Penile/Preputial Island Flap Urethroplasty for Urethral Stricture. The Journal of Urology, 134, 474-475.

https://doi.org/10.1016/S0022-5347(17)47244-2

[15] McAninch, J.W. (1993) Reconstruction of Extensive Urethral Strictures Circular Fasciocutaneous Penile Flap. The Journal of Urology, 149, 488-491.

https://doi.org/10.1016/S0022-5347(17)36125-6

[16] Carney, K.J. and McAninch, J.W. (2002) Penile Circular Fasciocutaneous Flaps to Reconstruct Complex Anterior Urethral Strictures. Urologic Clinics of North America, 29, 397-409. https://doi.org/10.1016/S0094-0143(02)00046-0

[17] El-Kasaby, A.W., et al. (1993) The Use of Buccal Mucosa Patch Graft in the Management of Anterior Urethral Strictures. The Journal of Urology, 149, 276-278. https://doi.org/10.1016/S0022-5347(17)36054-8

[18] Burger, R.A., et al. (1992) The Buccal Mucosal Graft for Urethral Reconstruction: A Preliminary Report. The Journal of Urology, 147, 662-664. https://doi.org/10.1016/S0022-5347(17)37340-8

[19] Kaboré, F.A., Zango, B. and Paré, A.K. (2015) Analyse rétrospective du traitement 
chirurgical d'une série de 148 cas de rétrécissements de l'urètre masculin au Burkina Faso. Revue uro andro Sénégal, 1, 201-204.

http://revue-uroandro.org/index.php/uro-andro/article/view/54

[20] Hmida, W., Othmen, M.B., Bako, A., Jaidane, M. and Mosbah, F. (1019) Penile Skin Flap: A Versatile Substitute for Anterior Urethral Stricture. IBJU, 45, 1057-1063. https://doi.org/10.1590/s1677-5538.ibju.2018.0652

[21] Alsagheer, G.A., Fathi, A., Abdel-Kader, M.S., Hasan, A.M., Mohamed, O., Mahmoud, O. and Abolyosr, A. (2018) Management of Long Segment Anterior Urethral Stricture ( $\geq 8 \mathrm{~cm}$ ) Using Buccal Mucosal (BM) Graft and Penile Skin (PS) Flap: Outcome and Predictors of Failure. IBJU, 44, 163-171. https://doi.org/10.1590/s1677-5538.ibju.2017.0083

[22] Mathur, R., Aggarwal, G., Satsangi, B., Khan, F. and Odiya, S. (2011) Comprehensive Analysis of Etiology on the Prognosis of Urethral Strictures. International Brazilian Journal of Urology, 37, 362-369.

https://doi.org/10.1590/S1677-55382011000300010

[23] Stein, D.M., Thum, D.J., Barbagli, G., et al. (2013) A Geographic Analysis of Male Urethral Stricture Aetiology and Location. BJU International, 112, 830-834.

https://doi.org/10.1111/j.1464-410X.2012.11600.x

[24] Xu, Y.M., Qiao, Y., Sa, Y.L., Wu, D.L., Zhang, X.R., Zhang, J., et al. (2007) Substitution Urethroplasty of Complex and Long-Segment Urethral Strictures: A Rationale for Procedure Selection. European Urology, 51, 1093-1098. https://doi.org/10.1016/j.eururo.2006.11.039

[25] McAninch, J.W. and Morey, A.F. (1998) Penile Circular Fasciocutaneous Skin Flap in 1-Stage Reconstruction of Complex Anterior Urethral Strictures. The Journal of Urology, 159, 1209-1213. https://pubmed.ncbi.nlm.nih.gov/9507836 https://doi.org/10.1016/S0022-5347(01)63558-4

[26] Da Silva, E.A. and Sampaio, F.J. (2002) Urethral Extensibility Applied to Reconstructive Surgery. The Journal of Urology, 167, 2042-2045.

https://doi.org/10.1016/S0022-5347(05)65079-3 


\section{Reponse Letter}

1) Several urethroplasty techniques have been used depending on the length of the stenosis, the presence of fistula or depending on the existence of suppuration. Among these surgical techniques, penile skin flap urethroplasty accounted for $19.44 \%$.

2) All interventions were carried out by a team of 3 urologists including a senior present at all interventions.

3) All patients with single or multiple urethral strictures greater than $2 \mathrm{~cm}$ without urethral fistula were included except stenoses due to atrophic lichen sclerosus.

4) We used tubularized penile skin flap successfully in one stage in our patients. Its indication in the treatment of long non-fistulized urethral stenoses, gave very good results.

5) Good urination was characterized by an immediate onset, a jet drawing a parabola, a frank ending without late drops and an absence of abdominal thrust.

6) We have made the grammatical corrections to the extent of our linguistic knowledge. We wrote the manuscript in French before translating it into English. We are at your disposal to make any correction suggests to improve the quality of work. 